\title{
SCÉVOLE DE SAINTE-MARTHE, Euvres complètes. VI. Gallorum doctrina illustrium elogia
}

\section{Maurizio Busca}

\section{OpenEdition}

\section{Journals}

\section{Edizione digitale}

URL: https://journals.openedition.org/studifrancesi/22511

DOI: 10.4000/studifrancesi.22511

ISSN: 2421-5856

\section{Editore}

Rosenberg \& Sellier

\section{Edizione cartacea}

Data di pubblicazione: 1 avril 2020

Paginazione: 164-165

ISSN: 0039-2944

\section{Notizia bibliografica digitale}

Maurizio Busca, «scévole de SAINTE-MARThe, EFuvres complètes. VI. Gallorum doctrina illustrium elogia», Studi Francesi [Online], 190 (LXIV | I) | 2020, online dal 01 avril 2020, consultato il 03 août 2021. URL: http:// journals.openedition.org/studifrancesi/22511 ; DOI: https://doi.org/10.4000/studifrancesi.22511

Questo documento è stato generato automaticamente il 3 août 2021.

\section{cc) (i) $\odot$}

Studi Francesi è distribuita con Licenza Creative Commons Attribuzione - Non commerciale - Non opere derivate 4.0 Internazionale. 


\title{
SCÉVOLE DE SAINTE-MARTHE, CEuvres complètes. VI. Gallorum doctrina illustrium elogia
}

\author{
Maurizio Busca
}

\section{NOTIZIA}

SCÉVOLE DE SAINTE-MARTHE, CEuvres complètes. VI. Gallorum doctrina illustrium elogia, édition chronologique avec introduction, notes et variantes par J. Brunel avec la collaboration de P. Martin, Genève, Droz, 2018, «Textes littéraires français», 710 pp.

1 Il lavoro di edizione delle opere complete di Scévole de Sainte-Marthe, avviato nel 2010 (si vedano, in questi "Studi", le segnalazioni dei cinque tomi già apparsi: n. 164, p. 399; n. 170 , pp. $442-443$; n. 172 , pp. $133-134$; n. 179 , p. 318 ; n. 183, p. 546), giunge a compimento con il volume dedicato alla raccolta degli Elogia. L'Avant-propos e l'Introduction di Jean Brunel (pp. 9- 31) illustrano le vicende editoriali e il contenuto di un'opera che Sainte-Marthe ha rimaneggiato e ampliato a più riprese negli ultimi anni della sua vita: un primo libro di Elogia è pubblicato nel 1598, mentre un secondo vede la luce nel 1602; i materiali che compongono questi due libri sono poi riorganizzati e arricchiti negli anni successivi, dando luogo a due edizioni curate dall'autore (una del 1606 , che adotta una scansione in quattro libri, e una del 1616, in cinque libri) e a una edizione postuma (1630, in cinque libri). L'editore sceglie di restituire il contenuto di ognuna delle cinque raccolte qui evocate fornendo però una sola volta il testo dei singoli componimenti, che appaiono in forma estesa nelle rispettive collocazioni di prima pubblicazione e sono invece richiamati con una sigla nelle raccolte successive. Le varianti testuali minori sono indicate in apparato, mentre nel caso di interventi estesi dell'autore si è preferito presentare nel corpo stesso del testo i diversi stati redazionali. Il testo è accompagnato da una traduzione integrale (la prima ad essere pubblicata dopo quella di Colletet, risalente al 1644), da un apparato di note esplicative e 
bibliografiche, da una scelta di illustrazioni e da una serie di indici indispensabili per orientarsi nell'opera di Sainte-Marthe. Precisiamo che le pièces liminari che aprivano le varie edizioni degli Elogia non figurano in questo volume ma nel quinto della serie delle Euvres complètes. 